\title{
Belajar Dari Iran: Dialektika Agama dan Politik Pasca Khomeini
}

\author{
Saefur Rochmat \\ Universitas Negeri Yogyakarta
}

\begin{abstract}
Abstrak: Ehthesami dan Abrahamian menamakan Iran Pasca Khomeini sebagai the Second Republic dengan alasan yang berbeda. Sedangkan Halliday menamainya dengan post-akhundism. Tulisan ini ingin menampilkan dialektika agama dan politik yang berlangsung secara rasional, agar bisa dijadikan cermin bagi umat Islam di Indonesia. Tulisan ini menggunakan pendekatan sejarah multidimensional agar didapat pandangan yang lebih utuh. Pendekatan ini diharapkan dapat menampung baik pandangan Ehthesami yang lebih menekankan pada aspek ekonomi, dan pandangan Abrahamian yang lebih menekankan pada aspek budaya, maupun pandangan Halliday yang melihat keterlibatan ulama dalam politik. Modifikasi sistem pemerintahan Islam Iran pasca Khomeini tidak dapat dilepaskan dari dasardasar perubahan yang telah diletakkan oleh Khomeini.
\end{abstract}

Kata kunci: agama, politik, Iran, dialektika, dan Khomeini.

\begin{abstract}
Ethesami and Abrahamian named Iran Pst Khomeini as the Second Republic with a different reason. While Halliday name it with post-achundism. This paper is conduxted to show dialectic of religion and politics that goes rationally, so it can be used as the reflectionfor Moeslem in Indonesia. This paper used a multidimensional historical approach in order to get a complete view. This approach is expected to accomodate both of Enthesami view which focus on economic aspectsm and Abrahamian view which focus on cultural aspects, also Halliday view which saw the involvement of clerics in politics. The modification of Islamic system of government of Iran post Khomeini can not be separated from the basics of the changes that have been placed by Khomeini.
\end{abstract}

Key words: religion, politics, Iran, dialectic, and Khomeini.

\section{Pendahuluan}

Sebutan Iran pasca Khomeini dulu hanya untuk mempermudah penganalisaan permasalah tersebut. Berbeda dengan Ehteshami (1995) yang berkeyakinan bahwa Iran telah memasuki era baru setelah kematian Khomeini pada tahun 1989, karena Iran berjalan moderat dan menempuh pendekatan pragmatis dengan lebih menekankan pada pembangunan bidang ekonomi dibandingkan dengan bidang politik. Konsekuensinya, Iran pasca Khomeini telah gagal mempertahankan posisi Khomeini yang konsisten untuk menjadikan Iran sebagai blok alternatif di luar dua blok yang telah ada, baik blok kapitalis maupun blok komunis. Dia melihat Iran sedang menuju ke dalam negara kapitalis.

Menurut penulis ada yang ganjil dengan spesifikasi bahwa Iran pasca Khomeini sebagai the second republic. Kenyataannya Ehteshami nampak kelabakan dengan sikap Iran yang tetap pada pendirian Khomeini yang menuntut hukuman mati terhadap Salman Rushdi. Memang penggolongan revolusi Islam Iran yang menitikberatkan lebih pada aspek ekonomi kurang memuaskan. Sebaliknya Abrahamian (1993) berkeyakinan bahwa revolusi Islam Iran sebagai 
gerakan populis lebih menekankan kepada pendekatan budaya daripada pendekatan ekonomi. Karena itu, Republik Islam Iran dapat mengatasi secara mengagumkan tekanan kekuatan luar, seperti perang yang dilancarkan Irak terhadap Iran. Memang benar Ali Khamaeni, Pemimpin Spiritual pengganti Khomeini, telah menjalankan kebijakan yang bersifat pragmatis dalam sektor ekonomi, dengan konsekuensi dalam bidang politik Iran tidak lagi memaksakan diri menjadi blok alternatif dalam percaturan politik internasional. Memang sektor politik dan ekonomi saling terjalin erat untuk menghasilkan suatu kekuatan dunia.

Sementara itu Halliday (1997) menyebut regim pasca Khomeini sebagai post-akhundism, karena Iran tidak lagi dikuasai oleh politisi ulama (ulama tingkat rendah). Adalah tidak tepat mengatakan Khomeini sebagai akhund karena dia memenuhi persyaratan untuk melakukan ijtihad. Sebaliknya, Iran pasca Khomeini menjadi lebih bersifat politis, karena bila dilihat dari kepemimpinan religious, Ali Khamaeni belum mampu menjabat sebagai Pemimpin Spiritual. Faktor lain yang tidak mendukung argumentasi Halliday (1997) tersebut adalah ulama masih mengendalikan kekuasaan politik dari tingkat elit sampai pegawai rendahan di pedesaan.

Memang Halliday (1997) tidak meramalkan kejatuhan regim ulama, melainkan meramalkan bahwa regim ulama akan menempuh jalan yang lebih moderat secara politik karena dipengaruhi oleh tiga hal: pertama, situasi politik dan sosial di dalam negeri, termasuk masyarakat Iran di pengasingan; kedua, tekanan dunia internasional; dan ketiga, sejarah dan tradisi Iran (Halliday, 1997: 44).

\section{Kajian Literatur dan Pembahasan}

\section{Dasar-Dasar Perubahan Iran Pasca Khomeini}

Khomeini merupakan seorang pemimpin kharismatik, disamping sebagai pemimpin revolusi Islam Iran pada tahun 1979, dia diakui sebagai Marja'i Taqlid mutlaq (pemimpin agama tertinggi dalam Islam Syiah). Berdasarkan Undang Undang Dasar Republik Islam Iran tahun 1979 dalam pasal 107 Khomeini ditetapkan sebagai pemimpin spiritual (Faqih) yang mempunyai kekuasaan otoritatif atas masalah politik dan agama. Tidak ada seorangpun yang berani mengusik kedudukan tersebut. Beberapa fraksi yang saling bersaing untuk mendapatkan kekuasaan, kecuali kelompok Marxisme/Komunisme, hanya ingin mendapatkan kepercayaan darinya dan akan memperebutkan kekuasaan sepeninggalnya.

Secara pragmatis Khomeini membentuk Dewan Ahli (Majelis-e Khobregan) untuk memilih penggantinya yang akan menyelamatkan Velayate Faqih (pemerintahan ulama), karena tidak ada pemimpin kharismatis yang dapat meyakinkan semua kelompok untuk menggantikan posisinya sebagai Pemimpin Spiritual (Imam) yang berkuasa atas urusan politik dan agama sekaligus. Pada tanggal 22 November 1985, Dewan Ahli ini berhasil memilih ayatollah ozma (ayatollah besar) termuda, Husain Ali Montazeri, sebagai pengganti Khomeini. Hal itu terjadi karena ayatollah ozma yang lebih senior tidak mau menduduki pos Pemimpin Spiritual yang dirasakan lebih bersifat politis, disamping pertimbangan usianya sudah lanjut. Akan tetapi, posisi Montazeri ditantang faksi lain yang mempertanyakan kapasitas kepemimpinannya baik dalam bidang religious ataupun politik. Mereka mengklaim Montazeri tidak memenuhi persyaratan teologi untuk memangku jabatan Faqih (Imam), yaitu masih keturunan Nabi Muhammad SAW dan statusnya belum menjadi rujukan utama dalam bidang hukum Islam (Mackey, 1996: 353).

Perpecahan terus berlanjut antara Montazeri di satu pihak dengan ayatolah Ali Khamaeni dan Hojatuleslam Rafsanjani di lain pihak. Yang pertama mewakili kelompok radikal dalam politik luar negeri dan tidak membenarkan hubungan rahasia dengan Israel dan Amerika dalam pembelian senjata perang melawan Irak. Sementara yang kedua mewakili kelompok moderat yang mau bekerjasama dengan pihak Israel dan Amerika untuk melindungi negaranya dari invasi Presiden Saddam Husain dari Irak. Persaingan di antara berbagai kelompok tersebut masih dalam kontrol Khomeini, bahkan dia menyediakan wadah yang menampung segala persoalan untuk diselesaikan, yaitu Badan Penentu Kebijakan. Dengan dibentuknya badan ini, Khomeini tidak harus terlibat langsung dalam setiap persaingan yang terjadi. Khomeini akan 
terjun bila memang diperlukan. Dia dapat melakukan itu karena dia pemimpin kharismatik yang sekaligus dapat memerankan diri sebagai pemimpin politik dan pemimpin agama.

Penulis mengklasifikasi perpecahan pada setiap aspek, yaitu ekonomi, sosio-kultural, politik dalam negeri, maupun politik luar negeri. Sebagian rakyat tidak setuju dalam kebijakan ekonomi, tetapi mereka mempunyai pendirian yang sama dalam bidang politik luar negeri. Hal tersebut menunjukkan bahwa proses dialektis dalam menentukan kebijakan yang Islamis, dimana ditentukan oleh kepentingan politik suatu kelompok.

Kasus Iran-gate, sebagai contoh, lebih bersifat politis daripada perbedaan interpretasi dalam menafsirkan ajaran Islam. Mehdi Hashemi, saudara laki-laki dari menantu laki-laki Montazeri, memanfaatkan kasus tersebut untuk menyingkirkan lawan politiknya dari kelompok moderat yang bersedia bekerjasama dengan pihak Barat untuk mendapatkan bantuan senjata. Kasus tersebut dimulai di Teheran pada tahun 1986 dengan diadakannya pertemuan antara missi Amerika dibawah pimpinan Oliver L. North dan Robert McFarlane dengan Kepala Komisi Luar Negeri parlemen, yaitu Muhammad Ali Hadi. Missi Amerika berjanji akan memberikan bantuan peralatan militer sebagai ganti dari pelepasan sandera. Khomeini tidak suka dengan cara Montazeri memecahkan permasalah tersebut karena hal itu berpotensi besar terjadinya kekacauan di dalam negeri Iran.

Kelompok moderat berhasil menghukum mati Mehdi Hashemi karena terlibat penculikan duta besar Syiria di Libanon. Dia juga dituduh membantu SAVAK. Sementara itu Montazeri dan puterinya diasingkan ke Mashad (Sihbudi, 1989: 199-200). Kemudian Khomeini lewat anaknya ayatollah Ahmad mengeluarkan memoran-dum setebal 110 halaman yang berisi tuduhan bahwa Montazeri telah bekerjasama dengan musuh untuk menghancurkan negara. Memang Khomeini merehabilitasi Montazeri, tetapi popularitasnya telah menurun jauh setelah dia mengkritik kegagalan pemerintahan pada perayaan ke-10 hari jadi Republik Islam Iran. Akhirnya Montazeri mengundurkan diri dari posisinya sebagai calon pengganti Khomeini pada tanggal 27 Maret 1989 (Tempo, 10 Juni 1989).
Setelah kasus Iran-gate, Khomeini mencari alternatif lain untuk menyelamatkan Velayat-e Faqih dengan membentuk Dewan Perubahan Konstitusi pada tanggal 24 April 1989 yang anggotanya terdiri dari 25 orang yang dipilih oleh Khomeini untuk melakukan ratifikasi Konstitusi 1979. Dewan mempunyai tugas menyiapkan draft amandemen perubahan Konstitusi untuk membentuk sistem pemerintahan yang kuat dan merubah kriteria orang yang dapat menduduki Faqih karena adanya perubahan konstelasi politik. Karena penggantinya bukan Marja'i Taqlid mutlaq maka pembentukan sistem pemerintahan pusat yang kuat merupakan sine qua non.

Dalam referendum, rakyat menyetujui perubahan Konstitusi yang isinya antara lain mengubah kriteria Faqih yang tercantum pada Konstitusi 1979. Konstitusi 1979 menetapkan syarat Faqih adalah seorang yang menyandang gelar ayatollah ozma dan diamandemen menjadi tidak harus seorang ayatollah ozma dengan syarat mempunyai kemampuan agama yang tinggi (berdasarkan kriteria tertentu) dan mengetahui permasalahan zamannya (Gieling, 1997: 777). Dengan demikian, jabatan Faqih yang murni bersifat religious menjadi bersifat politis. Karenanya otoritas Faqih menjadi tidak sebesar Khomeini karena persyaratannya dilonggarkan. Memang Faqih adalah pemimpin agama, tetapi mempunyai pengaruh politik yang besar bagi Islam Syiah.

Perubahan Konstitusi untuk menghindari ambigu mengenai peran dan tanggung jawab (fungsi dan kedudukan) setiap lembaga negera, disamping keinginannya untuk membentuk sistem pemerintahan pusat yang kuat. Pada masa pemerintahan Khomeini, masalah Konstitusi bukanlah menjadi masalah yang mendesak karena dia berkompeten untuk menduduki kepemimpinan religious dan politik sekaligus, disamping dia dapat memerankan diri secara meyakinkan sebagai mediator di antara berbagai kekuatan politik dan kelompok beragama.

Khomeini berusaha mengarahkan siapa penggantinya untuk menghindari perpecahan, melalui surat wasiat yang menyatakan Ali Khamaeni sebagai penggantinya, walaupun Dewan Ahli berhak memutuskan siapa yang akan menduduki jabatan Faqih (Imam) tanpa harus 
mempertimbangkan isi surat wasiat tersebut. Hal itu dilakukan Khomeini karena pengantinya tidak mempunyai kapabilitas sebagai pemimpin religious maupun sebagai pemimpin politik sekaligus.

\section{Modifikasi Sistem Pemerintahan Iran Pasca Khomeini}

Khomeini meninggal pada tanggal 9 Juni 1989 sebelum amandemen Konstitusi disahkan oleh parlemen. Namun, dia telah meletakkan dasardasar bagi sistem pemerintahan pusat yang kuat. Calon pengganti yang ditulis dalam surat wasiat diterima dan diresmikan oleh Dewan Ahli. Sementara untuk menggantikan fungsi mediatornya, Khomeini membentuk suatu badan yang bertugas memecahkan perbedaan dalam masalah legislasi antara Dewan Perwalian (Syurae Negahban) dengan Dewan Penasehat (Majlis-e Islami) pada bulan Februari 1988. Badan tersebut dinamai dengan Badan Penentuan Kebijaksanaan, yang anggotanya teridiri dari 13 orang.

Dengan demikian, Ali Khamaeni menindaklanjuti kebijakan yang direncanakan oleh Khomeini, yang menjadi prasyarat bagi perbaikan ekonomi seperti gencatan senjata dengan Irak, investasi dan pinjaman luar negeri, dan ratifikasi Konstitusi. Khomeini menerima gencatan senjata dengan Irak karena didorong sikap empati terhadap rakyatnya atau dia ingin menenangkan kemarahan para pengikutnya dari kelompok radikal. Khomeini sendiri merasakan keputusan gencatan senjata sebagai "keputusan yang lebih jelek daripada minum racun" (Reed, 1989: 2). Kemudian pada bulan Januari 1989 Khomeini juga menyetujui keinginan pemerintah Iran mendatangkan pinjaman luar negeri, dengan mengatakan bahwa Iran perlu mengundang negara-negara tetangga untuk berpartisipasi dalam pembangunan negaranya.

\section{Kekuasaan Pemimpin Spiritual (Faqih)}

Amandemen Konstitusi menempatkan posisi Faqih sebagai pemegang kekuasaan yang paling menentukan di Iran, disamping menginstitusionalkan mekanisme kekuasaan dan pembagian kekuasaan. Faqih (Pemimpin Spiritual) mendapat gelar Imam.

Amandemen Konstitusi berusaha mengkonsolidasikan kekuasaan religio-politik pasca
Khomeini, terutama yang berhubungan dengan seleksi dan tanggung jawab administrasi Faqih. Pasal 109 amandemen Konstitusi telah mengganti Dewan Kepemimpinan dengan seorang Faqih dengan tujuan untuk menciptakan stabilitas pemerintahan.

Amandemen ini tidak mengurangi kekuasaan ulama, tetapi terjadi pendistribusian kekuasaan ulama untuk menjamin prinsip checks and balances, suatu yang diamanatkan dalam Islam agar selalu bersikap moderat. Pembagian kekuasaan secara mencolok terjadi antara Faqih (Imam/Pemimpin Spiritual) dan presiden yang dapat menjamin prinsip checks and balances dalam menjalankan pemerintahan. Menurut amandemen yang baru, Faqih tidak dapat menghentikan Presiden dalam masa jabatannya, kecuali telah mendapatkan persetujuan dari parlemen dan Lembaga Peradilan. Posisi Presiden semakin kuat karena lembaga perdana menteri juga telah dihapuskan. Amandemen ini juga menggantikan jumlah anggota Dewan Peradilan Agung dari lima orang menjadi seorang (Reed, 1989: 37-40).

Faqih tidak hanya mengawasi jalannya pemerintahan, tetapi juga secara aktif mengawasi semua institusi yang berhubungan dengannya. Ehteshami (1995: 49) meringkas tugas dan tanggung jawab Faqih sebagai berikut:

(1) Supreme commander of the armed forces, (2) Determining the general policies of the IRI (in consultation with the Expediency Council), (3) Supervising the general implication of agreed policies, (4) Ordering referenda, (5) Power to declare war and peace and general troop mobilization, (6) Appointing and dismissing: (a) Members of the Council of Guardians, (b) Head of the judiciary, (c) Director of radio and television networks, (d) Chief of staff of the armed forces, (e) Commander-in-Chief of the IRGC, (f) Commander-in-Chief of the military and security forces, (7) Resolve differences and regulate relations among the three branches of the government, (8) Resolve, through the Expediency Council, problems which cannot be resolved by ordinary means, (9) Signing the decree naming the President after popular elections, (10) Impeaching the President for reasons of national interest pursuant to a verdict by the Supreme Court confirming his violation of his legal duties or a vote of no confidence by the Majlis. 
Faqih menjalankan kekuasaan melalui empat jalur utama, yaitu: pertama, melalui kantornya sendiri; kedua, melalui perwakilannya di setiap propinsi; ketiga, melalui perwakilannya di setiap organisasi/lembaga nasional; dan keempat, sebagai Panglima Militer Tertinggi. Melalui kantornya Faqih dapat mengikuti perkembangan politik yang terjadi; melalui perwakilannya di propinsi dia mendapatkan laporan tentang perkembangan politik di daerah. Bahkan ia memelihara pengaruh melalui perwakilan pada setiap organisasi/lembaga nasional (Ehteshami, 1995: 50).

Memang benar kekuasaan Imam Ali Khamaeni tidak sebesar Khomeini, tetapi kedudukan lembaga Faqih tetap kuat, bahkan lebih kuat karena Imam Ali Khamaeni ditetapkan secara legal menjadi pemimpin politik dan agama sekaligus. Keputusan semacam ini tentu tidak diperlukan oleh Khomeini. Tindakan legal ini ditempuh karena Ali Khamaeni belum diakui sebagai Marja'i Ttaqlid mutlaq. Penetapan sebagai Imam secara legal didasarkan pada pemikiran bahwa pemerintahan Islam sebagai bagian dari amanat Nabi memegang kekuasaan agama dan politik sekaligus. Dengan demikian, Khomeini berusaha membentuk supremasi kekuasaan politik atas kekuasaan agama dengan alasan menyelamatkan agama lebih penting daripada menerapkan hukum. Karenanya Khomeini berusaha mensubordinasikan kepemimpinan religious kepada Faqih.

Sebenarnya surat wasiat Khomeini yang memilih Ali Khamaeni sebagai penggantinya telah mengesampingkan perspektif teologis dari Velayat-e Faqih yang mengharuskan pemegang jabatan Faqih adalah seorang yang memenuhi syarat sebagai Marja'i Taqlid yang menjadi rujukan bagi semua orang Syiah. Khomeini merevisi teori Velayat-e Faqih karena beberapa ulama senior tidak ingin terlibat dalam urusan politik praktis atau mereka tidak memiliki keahlian yang memadai dalam bidang politik. Hal tersebut menghasilkan dua cabang kepemimpinan. Pertama, Faqih yang berfungsi sebagai Pemimpin Spiritual dan kedua, Marja'i Taqlid yang menjalankan kepemimpinan religious. Akan tetapi Khomeini mendesakkan bahwa Faqih menjadi sumber panutan bagi umat Syiah dan semua orang Iran, karena Faqih menduduki posisi wali al-amri dan Marja'i Taqlid sebagai kelanjutan pemerintahan Nabi Muhammad SAW (Gieling, 1997: 3-4).

Praktisnya Faqih juga tidak dapat mengesampingkan Marja'i Taqlid yang menduduki Dewan Penentuan Kebijakan, dimana Faqih harus mendiskusikan masalah penting dengannya (Ehteshami, 1995: 52).

\section{Kekuasaan Presiden}

Pembagian kekuasan terjadi antara Faqih dan Presiden. Menurut Konstitusi ini, seperti dikutip Ehteshami (1995: 37-38) presiden dihormati dalam kalimat berikut:

Next to the Leader, the President of the Republic is the highest official authority of the country who is responsible for the enforcement of the Constitution and presides over the executive power with the exception of those matters which directly relate to the Leader

Presiden Rafsanjani adalah presiden eksekutif pertama yang diberi kekuasaan begitu besar. Dia berusaha mengkonsolidasikan kedudukannya dan berusaha mengurangi pengaruh dari kelompok radikal dengan cara tidak mengangkat saingannya ke dalam kabinetnya dan posisi penting lainnya atau mengangkatnya ke dalam posisi jabatan yang bersifat seremonial dan posisi penasehat yang tidak berhubungan langsung dengan pembuatan keputusan penting lainnya.

Dia secara perlahan melepaskan monopoli negara dalam bidang ekonomi, dan sebaliknya memberikan kesempatan kepada sektor swasta dan investor luar negeri dalam pembangunan ekonomi. Sebenarnya Khomeini telah mengizinkan pinjaman luar negeri ataupun investasi pihak asing, namun semasa Khomeini investor asing belum mau masuk. Atas dasar itu Ehteshami (1995: 100) berkeyakinan bahwa jika pernah eksis model sistem revolusi Islam maka itu terjadi pada masa Imam Khomeini, dan tahun 1989 menjadi pudar karena pertimbangan ekonomi menghalangi pandangan politik.

Politik luar negeri yang fleksibel dapat diperankan oleh Rafsanjani. Seperti diakui sendiri oleh Rafsanjani, perubahan haluan ini diisyaratkan oleh Khomeini. Hal ini terjadi ketika ekonomi Iran sangat memprihatinkan. Pada waktu itu Khomeini 
menyarankan untuk mencari bantuan tetangganya di sebelah Utara (eks-Uni Soviet). Hal ini merupakan langkah yang realistik, ketika Iran mengalami ketegangan dengan dunia Barat karena kasus Salman Rushdi (Suara Merdeka, 24 Juni 1989: vii). Langkah ini ditempuh untuk mengurangi ketergantungan perdagangan dengan dunia Barat maupun Jepang (Tempo, 6 Juni 1989).

Memang perubahan politik dengan Amerika masih menunggu waktu yang tepat. Hal ini karena jawaban Khomeini yang mengatakan: Politik luar negeri Iran tak akan berubah. Karena itu, Rafsanjani menyatakan dengan tegas bahwa Iran siap bersahabat dengan semua negara kecuali Amerika, Israel dan Afrika Selatan (Tempo, 2 September 1989).

Perubahan konstalasi politik yang drastis terjadi ketika terjadi krisis Teluk yang melibatkan Irak dan pasukan multinasional pimpinan Amerika. Krisis ini diawali dengan penyerbuan Irak ke Kuwait pada tanggal 2 Agustus 1990 dan menganeksasinya sebagai propinsi Irak. Krisis ini telah mengubah peta politik di kawasan ini secara drastis. Persekutuan Mesir-Irak dan Irak-GCC (Dewan Kerjasama Teluk) menjadi hancur. Begitu pula dengan organisasi regional seperti ACC (Dewan Kerjasama Arab : Mesir, Irak, Yaman dan Yordania); Persekutuan Negara-Negara Arab Maghribi: Libya, Aljazair, Maroko dan Tunisia) serta Liga Arab sendiri hancur (Sihbudi, 1992: 89-90).

\section{Simpulan dan Saran}

\section{Simpulan}

Sebelum meninggal, Khomeini telah melakukan ratifikasi/amandemen terhadap Konstitusi 1979 untuk menghindari ambigu fungsi dan wewenang setiap lembaga negera, disamping keinginannya untuk membentuk sistem pemerintahan pusat yang kuat. Dengan demikian, dia telah meletakkan fondasi yang kuat bagi jalannya pemerintahan. Memang dibawah pemerintahannya konstitusi belum menjadi masalah yang mendesak, karena memang dia kompeten memegang kepemimpinan religious dan politik sekaligus.

Modifikasi yang dilakukan oleh pengganti Khomeini, Imam Ali Khamaeni, merupakan tindak lanjut dari kebijakan Khomeini, seperti gencatan senjata dengan Irak, investasi dan pinjaman luar negeri, dan ratifikasi konstitusi. Dengan kata lain, Iran pasca Khomeini merupakan kelanjutan dari kebijakan Khomeini sebelumnya. Dengan demikian sebutan the second republic oleh Ehteshami dan post-akhundism oleh Halliday (1994) harus dilihat dari perspektif sejarah multidimensional agar memperoleh pandangan yang utuh.

\section{Saran}

Indonesia bisa belajar dari Iran dalam mensikapi dialektika agama dan politik. Bukan berarti kita harus meniru jalan yang telah ditempuh Iran, karena situasi dan kondisi, serta konteksnya yang berbeda. Dari Iran kita tahu bahwa pemikiran agama bukan sesuatu yang sakral, sehingga dimungkinkan untuk melakukan reformasi sesuai dengan perubahan situasi dan kondisi.

Indonesia tidak perlu menjadi negara Islam seperti Iran, karena berbeda dengan Iran, penduduk Indonesia sangat plural, sehingga penerapan syariah Islam yang legal formal tidak tepat, bahkan bisa menimbulkan kekerasan yang tentu bertentangan dengan misi agama yang humanis. Di Indonesia, pendekatan syariah Islam yang substansial lebih tepat karena memungkinkan kita melakukan kerjasama dengan penganut agama lain dalam rangka menegakkan hukum nasional yang yang handal.

\section{Pustaka Acuan}

Abrahamian, Ervand. 1993. Khomeinism. California: University of California Press.

Ehteshami, Anoushiravan. 1995. After Khomeini: The Iranian Second Republic. London: Routledge.

Gieling, Saskia. 1997. The Marja'iya in Iran and the Nomination of Khamaeni in December 1994. Middle Eastern Studies Vol. 33 No. 4.

Halliday, Fred. 1997. Post-Akhundism in Iran. Index on Censorship Vol. 26 No. 4.

Mackey, Sandra. 1996. The Iranians: Persia, Islam, and the Soul of a Nation. New York: A Plume Book. 
Reed, Fred. 1989. A Nation in Turmoil: Iranians Try to Redefine their Revolution. http://Iw1fd.hotmail.msn.com/cgi-G893901459.8\&len=13523.

Suara Merdeka, 24 Juni 1989.

Tempo, 6 Juni 1989.

, 10 Juni 1989.

, 2 September 1989. 